\title{
Determinants of the decline in mortality from acute myocardial infarction in England between 2002 and 2010: linked national database study
}

The authors of this Research paper (BMJ 2012;344:d8059, doi:10.1136/bmj.d8059) have informed us that an administrative error led to some incorrect values being published in table 2 under the columns "Event rate (per 100 000)" and "Mortality rate (per 100000 )." This is due to the fact that all rates were originally calculated per 10000 but this was later changed to 100000 . While the values in the rows for "All ages" and " $<75$ " reflect this change, data in age specific rows do not. This error does not affect any other part of the table, the text, or the conclusions of the paper, and a corrected version of the table can be found below.

Cite this as: BMJ 2013;347:f7379

(๑) BMJ Publishing Group Ltd 2013 


\section{Table}

\begin{tabular}{|c|c|c|c|c|c|c|c|c|c|c|c|c|c|c|c|}
\hline \multirow[b]{2}{*}{$\begin{array}{l}\text { Age } \\
\text { group }\end{array}$} & \multicolumn{4}{|c|}{ Event rate (per 100 000) } & \multicolumn{4}{|c|}{ Case fatality rate (\%) } & \multicolumn{5}{|c|}{ Mortality rate (per 100000 ) } & \multicolumn{2}{|c|}{$\begin{array}{c}\text { Contribution to } \\
\text { mortality } \\
\text { decline§ }\end{array}$} \\
\hline & 2002 & 2010 & $\begin{array}{c}\text { Overall } \\
\text { change } \\
(\%)\end{array}$ & $\begin{array}{c}\text { Annual } \\
\text { trend } \\
(\%)\end{array}$ & 2002 & 2010 & $\begin{array}{c}\text { Overall } \\
\text { change } \\
(\%)\end{array}$ & $\begin{array}{c}\text { Annual } \\
\text { trend } \\
(\%)\end{array}$ & 2002 & 2010 & $\begin{array}{c}\text { Overall } \\
\text { change } \\
(\%)\end{array}$ & $\begin{array}{c}\text { Annual } \\
\text { trend } \\
(\%)\end{array}$ & $\begin{array}{l}\text { Estimated } \\
\text { annual } \\
\text { trend‡ }(\%)\end{array}$ & $\begin{array}{c}\text { Event } \\
\text { rate (\%) }\end{array}$ & $\begin{array}{c}\text { Case } \\
\text { fatality } \\
\text { rate (\%) }\end{array}$ \\
\hline \multicolumn{16}{|l|}{ Men: } \\
\hline $30-54$ & 119 & 88.1 & -26 & $-3.2^{\star}$ & 17.6 & 13.8 & -22 & -2.7 & 20.2 & 12.3 & -39 & $-5.7^{\star}$ & -5.9 & 55 & 45 \\
\hline $55-64$ & 468 & 317 & -32 & -4.4 & 25.0 & 14.2 & -43 & -3.2 & 112 & 57.8 & -49 & $-7.7^{\star}$ & -7.6 & 58 & 42 \\
\hline $65-74$ & 897 & 533 & -41 & -6.2 & 37.2 & 19.5 & -48 & -3.8 & 313 & 137 & -56 & -10.1 & -10.0 & 62 & 38 \\
\hline $75-84$ & 1611 & 1017 & -37 & -5.7 & 50.4 & 28.0 & -44 & -3.7 & 760 & 347 & -54 & -9.7 & -9.5 & 61 & 39 \\
\hline$\geq 85$ & 2544 & 1987 & -22 & -3.2 & 61.2 & 37.9 & -38 & -3.3 & 1450 & 848 & -42 & -7.0 & -6.5 & 49 & 51 \\
\hline$<75$ & 156 & 104 & -34 & -4.7 & 28.9 & 22.1 & -23 & -3.5 & 41.4 & 20.3 & -51 & -8.6 & -8.2 & 57 & 43 \\
\hline All ages & 230 & 154 & -33 & -4.8 & 42.0 & 32.1 & -24 & -3.6 & 78.7 & 39.2 & -50 & -8.6 & -8.3 & 57 & 43 \\
\hline \multicolumn{16}{|l|}{ Women: } \\
\hline $30-54$ & 24.0 & 21.2 & -12 & $-1.2^{*}$ & 20.1 & 13.3 & -34 & -4.9 & 4.6 & 2.7 & -41 & $-5.9^{\star}$ & -6.1 & 20 & 80 \\
\hline $55-64$ & 140 & 90.3 & -36 & $-4.8^{*}$ & 24.8 & 17.4 & -30 & -4.8 & 32.5 & 14.9 & -54 & $-9.3^{*}$ & -9.6 & 50 & 50 \\
\hline $65-74$ & 408 & 237 & -42 & -6.7 & 37.2 & 25.3 & -32 & -5.1 & 143 & 54.6 & -62 & -11.6 & -11.8 & 56 & 44 \\
\hline $75-84$ & 898 & 597 & -34 & -5.2 & 50.7 & 35.8 & -29 & -4.5 & 423 & 190 & -55 & -9.9 & -9.7 & 53 & 47 \\
\hline$\geq 85$ & 1667 & 1395 & -16 & -2.7 & 61.5 & 45.7 & -26 & -3.7 & 970 & 574 & -41 & -6.8 & -6.3 & 42 & 58 \\
\hline$<75$ & 51.7 & 34.1 & -34 & -5.0 & 29.2 & 19.9 & -32 & -5.0 & 14.9 & 6.3 & -58 & -10.3 & -10.0 & 50 & 50 \\
\hline All ages & 95.4 & 66.0 & -31 & -4.5 & 42.2 & 29.9 & -29 & -4.2 & 37.3 & 17.7 & -53 & -9.1 & -8.7 & 52 & 48 \\
\hline
\end{tabular}

${ }^{*} \mathrm{P}>0.05$.

$\dagger(1-[$ rate in 2010]/[ rate in 2002]) $\times 100$.

$\ddagger$ Based on average annual trends in event rate and case fatality.

$\S$ (event or case fatality annual trend/estimated mortality trend) $\times 100$. 